\title{
MIASTENIA GRAVE FAMILIAR
}

\author{
RELATO DE CASO EM GEMEAS IDENTICAS
}

\author{
ELZA DIAS-TOSTA * MARIA DE FATIMA MACHADO AGUIAR** \\ HAMILTON BARBOSA * - SUZETE SILVA LEME VILELA **
}

\begin{abstract}
RESUMO - Trata-se do sétimo relato da literatura mundial de casos de miastenia gravis em gêmeos homozigóticos em que ambos são acometidos. O homozigotismo foi provado com certeza por estudo de HLA e a forma adquirida da doença foi provada por determinação de niveis elevados de anticorpos anti-receptor de acetilcolina, havendo também niveis elevados de anticoroos antimúsculo estriado, sem outras evidências de timoma.
\end{abstract}

Familial myasthenia gravis: case report in identical twins.

SUMMARY - To the best of our knowledge this is the seventh case report of monozyyotic twins both affected by myasthenia gravis (MG). The monozygotism was proven by sex identity, blood group and HLA determinations (' $\mathrm{O}$ ' $\mathrm{Rh}+, \mathrm{A} 2, \mathrm{A19.2}, \mathrm{B} 40$, CW3). One paternal aunt was also affected and the three cases have high titles of anti-acetylcholine receptor antibodies and anti-striated muscle antibodies, which indicate an acquired form of MG. After several myasthenic crises the twins are now doing well with corticosteroid therapy. The paternal aunt has a more benign form of $\mathbf{M G}$, with ocular and limb involvement (grade IIa of Osserman) and was submitted to thymectomy. The authors discuss the use of corticosteroid for the infantile form of $M G$ instead of thymectomy, based on the immaturity of the immune system in the young age. The use of other immunosupressive drugs is not advisable because of potential hazardous development of neoplasms.

Apesar dos avanços obtidos no conhecimento sobre a etiopatogenia da miastenia grave (MG), reconhecendo-se imunecomplexos na junção mioneural 9 e até a heterogeneidade dos anticorpos anti-receptores de acetilcolina 23 , persistem controvérsias sobre a doença. $O$ estudo de gêmeos oferece oportunidade ímpar para observar o papel de fatores genéticos e ambientais em qualquer doença 14 e é sabido que esses fatores estão interligados: o genético, na determinação da susceptibilidade individual (talvez ligada a determinados HLA), que responderia à agressão ambiental desenvolvendo a doença autoimune 12 .

$\dot{E}$ por isso que consideramos justificável o presente registro, mormente por ter sido possivel a realização da tipagem HLA, a dosagem de anticorpos (Ac) antireceptor de acetilcolina (AchR) e antimusculo estriado. $O$ relato é de especial interesse também por envolver nâo só duas crianças gêmeas, como a tia paterna. Na literatura nacional existem já relatos de casos de $M G$ familiar em irmãos năo gemelares 3,10 .

\section{OBSERVAC̄ÕES}

Caso 1 - ERCS, admissão em 08-10-86 com 1 ano e 5 meses. Prinıeira gemelar, prematura, peso $1710 \mathrm{~g}$, quadro respirator.o grave iniciado nas primeiras horas de vida (insuficiência respiratória aguda) por membrana hialina, necessitando de assistencia respira-

* Neurologista do Hospital de Base do Distrito Federal (HBDF), PhD; ** Neurologista da Unidade de Pediatria do HBDF. 
tória por 10 dias em terapia intensiva (UTI). Apresentava-se hipotônica, hipoativa, com hipoxemia grave, dependente do respirador; ocorreu, como complicação, quadro pneumônico. Apresentou icterícia (por provável imaturidade hepática), necessitando de exsanguino-transfusão às 56 horas de vida. Alta com 31 dias de vida, em boas condições. Bom desenvolvimento neuropsicomotor, vacinaçōes completas; asma brônquica e pneumonia no primeiro ano de vida. Com a idade de 1 ano e 4 meses (agosto/86), apresentou ptose paipebral direita. seguida de estrabismo convergente à esquerda, após quadro de infecçáo de vias aéreas superiores. Quinze dias após o inicio do quadro, havia ptose palpebral bilateral, que piorava no decorrer do dia e melhorava após periodos de sono. Não havia fraqueza muscular, alteraçōes da marcha ou degilutiç̄o. Exame físico - Distrófica $(8200 \mathrm{~g})$, bom estado geral, pálida $+/ 4+$; à ausculta pulmonar, broncoespasmo leve; ausculta cardiaca normal; adbome sem visceromegalias. Sistema nervoso: facies miasteniea; mímica pobre; ptose palpebral bilateral, com discreto estrabismo convergente à esquerda; pupilas isocóricas e fotorreagentes; força muscular preservada; marcha normal; reflexos superficiais e profundos simetricos, normais; hiperativa; fala normal para a idade: deglutição normal. Exames complementares - Teste com prostigmine (Fig. 1): Positivo. Eletromiografia: Teste de estimulação repetitiva do nervo ulnar direito a $5 \mathrm{c} / \mathrm{s}$ antes e após tétano mostrou queda parcial da resposta muscular evocada (cerca de $6 \%$ ). RX de tórax não evidenciou alteraçōes. Tipagem sangüínea: ' $O$ ' $R h$

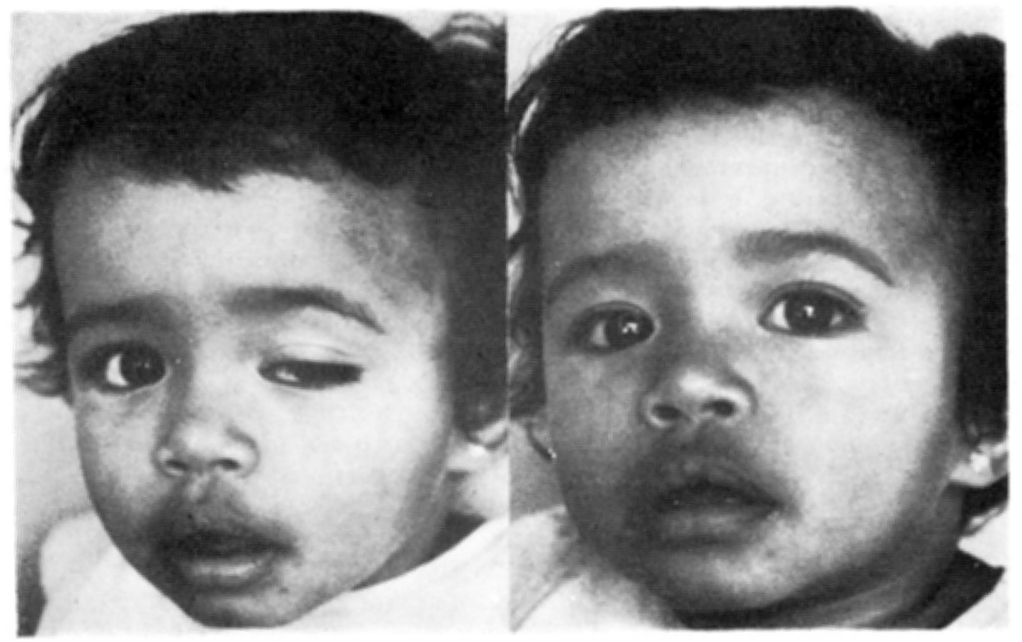

Fig. 1 - Caso 1 (ERCS). À esquerda, notar a oftalmoplegia. A direita, 5 minutos após uso de prostigmine intramuscular, motilidade ocular normal.

positivo. HLA: A19.2, B40, CW3. Ac anti AchR: $57 \mathrm{nM} / 1$ (normal ate $0,6 \mathrm{nM} / 1$ ). Ac antimúsculo estriado: 1/640 (normal até 1/20). Evoluçāo - Resposta inicial razoável com piridostigmina, até março/87 quajdo, durante pneumonia, apresentou insuficiência respiratória aguda, necessitando de assistência respiratória em UTI, com boa evolução. Em abril/87 houve nova piora do quadro bulbar, necessitando de alimentaçâo por sonda nasogástrica. Após resultado do título de anticorpos iniciou-se o uso de corticosteróides na dosagem de $2 \mathrm{mg} / \mathrm{kg}$, observando-se melhora a partir do quarto dia, sendo possível a retirada da sonda no $11^{\circ}$ dia, havendo regressāo completa do quadro no $30 \%$ dia. Ainda não se conseguiu a retirada total do corticosteróide - $5 \mathrm{mg} /$ dias alternados — por recrudescimento da sintomatologia.

Caso 2 - HRCS, atendimento ambulatorial em 05-12-86 com 1 ano e 7 meses. Segunda gemelar, prematura, peso $1300 \mathrm{~g}$, desconforto respiratório compativel a membrana hialina nåo necessitando, porém, de cuidados intensivos. Ficou internada para ganho ponderal e evoluiu bem do quadro respiratório. Bom desenvolvimento neuropsicomotor, vacinaçōes completas; asma brônquica. Com 1 ano e 6 meses (outubro/86), iniciou-se ptose palpebral bilateral com piora no decorrer do dia. A princípio, não havia relato de fraqueza muscular, alteracóes da fala ou deglutiçăo. Exame físico - Distrófica ( $9000 \mathrm{~g})$, bom estado geral, pálida $+/ 4+$; ausculta cardiopulmonar normal; abdome sem alterações. Sistema nervoso: 
facies miastênica; mímima pobre; ptose palpebral bilateral; pupilas isocóricas e fotorreagentes; marcha normal; força muscular preservada. Reflexos superficiais e profundos simétricos, normais; fala normal para a idade, deglutiçāo sem alteraçōes. Exames complementares Teste com prostigmine: positivo. Eletromiografia: teste de estimulação repetitiva nāo mostrou queda sionificativa da resposta muscular evocada; o registro de atividade muscular (músculos tibial anterior e biceps) mostrou-se normal, RX de tórax: imagem do timo no mediastino superior, com dimensōes normais para a idade. Tipagem sangüinea: ' $O$ ' Rh positivo. HLA: A19.2, B40, CW3. Ac anti AchR: $52 \mathrm{nM} / 1$. Ac antimúsculo estriado: 1/320. Evolução Resposta insatisfatória com piridostigmine. $\mathrm{Em}$ fevereiro/87 apresentou crise miastènica, com pneumoña de aspiração e insuficiência respiratória aguda (UTI), com alta em condições satisfatórias. Em março/87 teve nova insuficiência respiratôria aguda (IRA), com hẹnorragia digestiva, aspiraçăo e parada cárdio-respiratória. Recuperou-se com seqüelas neurológ cas. Em junho/87, nova internação em IRA, sendo introduzida prednisona (2mg/kg/dia) - após rezultado de anticorpos anti $A c h R$ - obtendo meihora do quadro miastênico. Com 40 dias iniciou-se a redução da prednisona. Atualmente com $5 \mathrm{mg} /$ dias alternados devido $\dot{a}$ mesma dificuldade da irmã.

Caso 3 - MIS, internação em 14-01-87, sexo feminino, cor parda, 22 arıs, ratural do DF. Aos 6 anos notou ptose palpebral esquerda, seguida, no ano seguinte, de ptose palpebral direita e diplopia horizontal bilateral. Somente observou limitação dos movimentos oculares aos 16 anos. Com 20 anos surgiu fraqueza vespertina, fatigabilidade importante. melhora com repouso. Aos 22 anos iniciou disfonia e cansaço ao mastigar. Tem sobrinhas gêmeas com miastenia gravis (casos 1 e 2); vitiligo aos 21 anos; cirurgia de correcão de ptose. Exame físico - ptose palpebral bilateral, que se acentua após 15 segundos de olhar vertical; ausência de movimentos oculares de abdução e de elevação; movimentos de adução limitados (p:or à esquerda) e também, vertical para baixo (pior à direita); fundo de olho miópico; diparesia facial e disfonia após contar até 100 . Exames complementares - Teste com prostigmine: positivo. Teste de estimulaşāo repetitiva do nervo ulnar e eletromiografia de agulha concēntrica em músculo de membro superior e inferior: normal. Biópsia muscular do quadriceps esquerdo: normal. RX simples e tomografia do mediastino: nāo apresentan! evidências de alteracões. HLA: A2, A19.2, B40, Y, CW3. Proteinas do soro: proteínas totais $7,6 \mathrm{~g} / \mathrm{dl}$, albumina $4,89 \mathrm{~g} / \mathrm{dl} \Theta$ globulinas alfa-1 $5,4 \% \quad(0,41 \mathrm{~g} / \mathrm{dl})$, alfa-2 $8,9 \%, \quad(0,68$ $\mathrm{g} / \mathrm{dl})$, beta $8,9 \%(0,68 \mathrm{~g} / \mathrm{dl})$, gama $12,5 \%(0,94 \mathrm{~g} / \mathrm{dl})$. T3: $150 \mathrm{mg} \%$; T4: $9 \mathrm{mg} \%$. Wvoluçāo Submetida a timectomia em 20-05-87; permaneceu por 24 horas na UTI e teve alta tm 8 dias. Nove meses adós a cirurgia foi reduzida a dose de Mestinon e permanrcia com a quadrı ocular inalterado.

\section{COMENTARIOS}

$O$ presente relato se refere a duas crianças do sexo feminino, HLA Al9.2, B40, CW3 7 e grupos sangüineos $\mathrm{O} R \mathrm{R}+$. Baseados na identidade de sexo, identidade de grupos satıgunuleos e de HLA, nós as consideramos gemeas monozigóticas de acordo com critérios já estabelecidos 18 . Não foram realizados análise cariotípica nenı estudo linfocitário, conforme preconizam outros autores 15 . Na literatura mundial estāo descritos apenas 6 pares de gêmeos 2,18 com determinação certa de monozigotismo e em que ambos são afetados pela MG sendo, portanto, este o sétimo (Tabela i). Por outro lado, a história familiar de $M G$ é também bastante rara, mesmo em revisâo tâo extensa como a que analisa um total de 702 casos com 27 pacientes em 12 familias 19. Em nosso relato, a história familiar revela a doença em duas geraçĩes e a transmissão através de herança paterna (Fig. 2).

$\mathrm{Na}$ forma familiar infantil transmitida por herança autossômica recessiva não foi encontrada anormalidade nos mecanismos imunológicos 1 . Esses casos serianı formas congênitas, diferentes portanto do presente relato, de acordo com os critérios estabelecidos 9,17 que consideram serem as formas de transmissão genética diferentes das adquiridas, por não terem anticorpos antiAchR, por terem resposta inadequada aos corticosteróides e por serem responsivos apenas aos anticolinesterásicos. Em nosso relato, apesar da evidência de transmissão genética autossômica recessiva com duas geraçôes afetadas, mesmo haplotipo HLA na tia paterna, nas gêmeas e no pai (este não acometido pela doença), ocorreu presença de nivel elevado de anticorpos antiAchR no soro das trếs pacientes, o que sugere a forma adquirida da doença.

Diz-se que a MG familiar tem início entre a segunda e terceira década, em consonância à maioria dos casos de MG adquirida, o que nāo ocorreu em nóssas pacientes, nas quais o inicio foi muito mais precoce, usual na miastenia congênita. Por isso, ao invés do critério temporal, preferimos utilizar critérios mais definidos 


\begin{tabular}{|c|c|c|c|c|c|}
\hline Autor & $\begin{array}{l}\text { Sexo/Idade } \\
\text { do incício } \\
\text { (anos) }\end{array}$ & $\begin{array}{l}\text { Duração do } \\
\text { 'follow'up' }\end{array}$ & $\begin{array}{c}\neq \text { em idade } \\
\text { de inicjo }\end{array}$ & $\begin{array}{l}\text { Prova relativa } \\
\text { de monozigotismo }\end{array}$ & $\begin{array}{l}\text { Músculas } \\
\text { afetados }\end{array}$ \\
\hline Aler 1966 *: & $F / 16$ & 4 anos & 2 anos & Aderuada & Generalizada \\
\hline $\begin{array}{l}\text { Osbone e } \\
\text { Bimeoch 1966: }\end{array}$ & $F / 2: 3$ & 1 andr & 2 anos & Certit & Generalizada \\
\hline Herman $1969 *$ & $F / 4$ & 10 anos & $\therefore$ allos & Adequadı & Oculofacial \\
\hline $\begin{array}{l}\text { McLean e } \\
\text { Mckone 1973\% }\end{array}$ & F/Nise: & 21 meses & 0 & Adequadu & Oculnbulbar \\
\hline $\begin{array}{l}\text { Alten e } \\
\text { Kissel } 1984:\end{array}$ & $\mathrm{F} / 22$ & 11. anos & $1 \sin 0$ & certa & Goneralizat \\
\hline $\begin{array}{l}\text { Murnhy e } \\
\text { Murnhy 1986* }\end{array}$ & $M_{i} / 7$ & $3: 4005$ & 1 ano & Certa & Generalizada \\
\hline $\begin{array}{l}\text { Dias-Tosta } \\
\text { et al. 1988* }\end{array}$ & $F / 1$ & 20 meses & 0 & Certa & Oculobulbar \\
\hline
\end{tabular}

Tabela 1 - Casos de MG em gemeos monozigoticos em que ambas foram afetados. * Monozigoticos, os dois gemeos afetados; Nxisc, nuscimpnto.

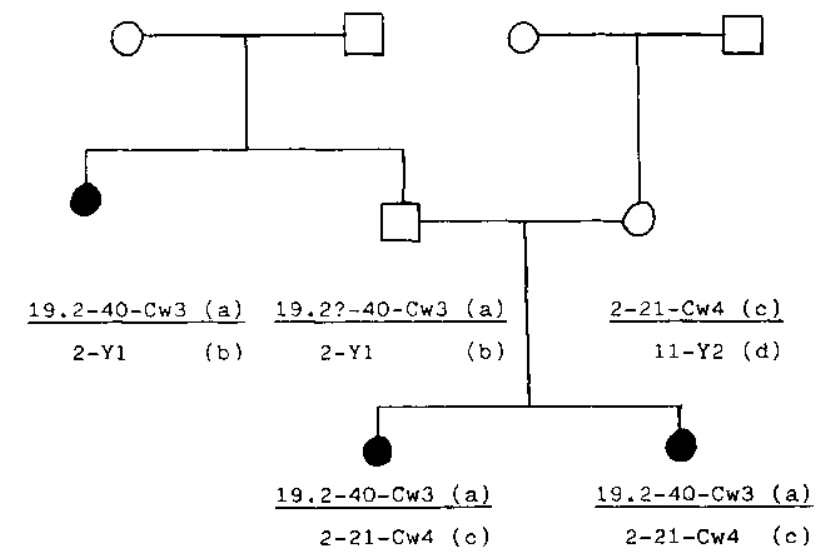

Fig. 2 - Heredourrumu dı fumiliat das gêmeas, mostramao "relacas da doencr com a linhagem paterna.

como a presença de anticorpos antiAchR para classificar como MG familiar, adquirida, à semelhança dos casos da $\mathrm{MG}$ juvenil relatados por Roach e col., que estudou 5 casos, iniciados em torno dos três anos e com risco de tecorrência familiar 20 . No presente relato, se os niveis altos de anticorpos antiAchR sugerem a natureza autoimune da doença, os níveis de anticorpos antimúsculo estriado sugerem tratar-se de tinoma em $84 \%$ dos casos 9 . No entanto, ainda que muito raro, ocorrem anticorpos antimúsculo estriado em pacientes jovens e também na ausência de timoma, conforme comentários de Lennon, sendo que a presença de casos falsopositivos na detecção de anticorpos antimúsculo estriado são mais raros ainda 16. 
O tratamento das crianças con corticosteróides foi diferente da timectomia preconizada para a tia, baseado inicialmente no intenso comprometimento do estado geral apresentado por elas, inclusive com crises de insuficiência respiratória. Em crianças, o valor da timectomia é mais discutivel que nos adultos devido, em parte, ao fato de que muitas das cirurgias propostas năo seren calcadas na análise de anticorpos antiAchR, podendo estar incluidos naquelas séries casos de miastenia congênita 11 sem indicaçao para cli urgia e pelo fato de nao se conbecer com precisão as implicações nocivas da cirurgia a longo prazo 5 nesta faixa etária. Na timectomia em idade precoce, espera-se que se modifique a competência imunológica 4 por diminuição de linfócitos T, tendo sido registrado um caso em que a criança após tal cirurgia ficou com anormalidade nas reações cutâneas de hipersensibilidáde tardia 21 . Devido à excelente resposta obtida com o corticosteróide, resolvemos aguardar mais tempo para indicar a cirurgia; no entanto, nossa preocupação cresce devido aos efeitos colaterais do uso prolongado da medicação, já que as tentativas de reduzir a dose foram acompanhadas de recrudescimento da sintomatologiá. Também não optamos pelo uso de outros imunossupressores näo esteróides devido ao risco de desenvolvimento de neoplasias, ainda que tenha sido recomendado por determinados autores após utilizarem a timectomia nessa faixa etária 2,4 .

Reforçando a etiologia autoimune da doença há a associaçăo, no presente caso, de asma brốnquica nas gêmeas e de vitiligo na tia. Estas doenças são consideradas de natureza imunológica, estando de acordo com o descrito na literatura, que evidencia quadro clínico semelhante na $M G$ familiar com a forma adquirida esporádica 13.

Em conclusāo, a importância na determinação do HLA está na demonstração do monozigotismo e do fator genético influenciante na etiopatogenia dessa doença automune $e, \epsilon m$ nosso caso, mostra que, acompanhando a aeterminação do HLA, a determinação da MG segue a linhagem paterna. Acreditamos, pois, que o inicio precoct ua doença e a presença de HLA idêntıco na linhagem paterna sugiram a influência genética na produção da MG nesta familia, conforme também demonstrado em $\mathrm{MG}$ autoimune experimental 6 , ainda que para se expressar possa este fator genético necessitar da interação de outros fatores ambientais 8 .

Agrudecimentos - Dr. Ricardo Manoel Oliveira, do Laboratório de Investigação em Reumatologia do HC da USP, que dosou os anticorpos; Dr. Antônio Vilaça, que tipou. o HLA (HDA, Brasilia); Dra. Maria Helena Chagas responsável pelos estudos neurofisiologicos (HBDF, Brasilia); Dr. Paulo Henrique Costa, que realizou os estudos histoquímicos (Hospital Sarah Kubitschek, Brasilia).

\section{REFERENCIAS}

1. Albers JW, Faulkner JA, Dorovini-Zis K, Barald KF Must RE, Ball RD - Abnormal neuromuscular transmission in an infantile myasthen $\mathrm{c}$ syndrome. Ann Neurol 16:28, 1984.

2. Allen N, Kìssel P, Pietrasink D, Perlow MJ - Myasthenia gravis in monozygotic twins. Arch Neurol $41: 994,1984$.

3. Assis LJ, Scaff $M$ - Familial myasthenia gravis. Arq Neuro-Psiquiat (São Paulo) 34:215, 1976.

4. Bjerre I, Hallberg A - Myasthen'a gravis: immunological studies in a young child treated with thymectomy and immunosupressive drugs. Neuropediatrics 14:106, 1983.

5. Cavanagh NPC - The role of thymectomy in childhood myasthenia. Develop Med Child Neurol 22:668, 1980 .

6. Christadoss P, Lennon VA, Kreo CJ, David CS - Genetic control of experimental autoimmune myasthenia gravis in mice. J Immunol 128:1141, 1982.

7. Dausset J, Pla M - HLA. Flamarion, Paris, 1985, pg 80.

8. Dick HM, Behan PO, Simpson JA, Durward WF - The inheritance of HLA antigens in myasthenia gravis. $J$ Immunogenet $1: 401,1974$.

9. Engel AG - Myasthenia gravis and myasthenic syndromes. Ann Neuroi 16:519, 1984.

10. Freitas MRG, Gomes SEG, Cincinatus $D$, Garcia JMM, Nevares MTM, Hahn MD Miastenia gravis familiar: registro de dois irmáos. Arq. Neuro-Psiquiat (São Paulo) 43:81, 1985 . 
11. Gieron MA, Korthals JK - Familial infantile myasthenia gravis: report of three cases with follow-up until adult life. Arch Neurol 42:143, 1985.

12. Harati $Y$, Niakan E, Bergman EW - Childhood dermatomyositis in nonozygutic twins. Neurology $36: 721,1986$.

13. Honeybourne D, Dyer PA, Muhr PD - Familial myasthenia gravis. J Neurol Neurosurg Fsychiat $45: 854,1982$.

14. Hrubeg $\mathrm{Z}$. Kobrinete $\mathrm{CD}$ - The study of human twins in medical research. $\mathrm{N}$ Engl J Med 310:435, 1984.

15. McLean $W$, McKone $R$, Sclem $W$ - Congenital myasthenia gravis in twins. Arch Neurol $29: 223,1973$.

16. Moore HJ, Woods EL - Myasthenia gravis: associated antibodies in asymptomatic thymoma. J Thorac Cardiovasc Surg $89: 308,1985$.

17. Mora M, Lambert EH, Engel AG - Synaptic vesicis abnormality in familial infantilf. myasthenia. Neurology $37: 206,1987$.

18. Murphy J, Murphy SF - Myasthenia gravis in identical twins. Neurology 36:78, 1986.

19. Namba T, Brunner NG, Brown SB, Mugurama M, Grob D - Familial myastheriia gravis: report of 27 pacients in 12 families. Arch Neurol 25:49, 1971.

20. Roach SE, Buonn G, McLean WT Jr, Grey Weaver $R$ Jr, Winstons-Sclem NC - Annual Meeting of the Child Neurology Society, 1985. pg 40 .

21. Scadding GK, Thomas HC, Havard CWH - The immunological effects of thymectomy in myasthenia gravis. Clin Exper Immunol 36:205, 1979. 